\title{
El legado de Henry Kissinger: algunas implicancias de su gestión
}

El retiro del Secretario de Estado Henry Kissinger constituye, sin duda, uno de los hechos más significàtivos del panorama internacional contemporáneo.

Difícil resulta imaginar el mundo sin él. Malogrando no pocas especulaciones, Kissinger no asumió el papel' de "profesor" en. el gobierno, más bien representa el típico exponente político, para el cual el poder constituye la medida de las acciones.

Pensando en Harvard hubo quienes, de la lectura meticulosa de alguna de sus obras, llegaron a definir el supuesto paradigma kissin- , geriano: la pentarquía de naciones. Otros ligaron el probable estilo del ex consejero y Secretario de Estado a la función de la tradicional diplomacia republicana, olvidando el carácter no partidista de Kissinger.

Partiendo de la base que existen intereses objetivos, pensamos que el análisis realista de la gestión Kissinger debe comenzar por definir el marco histórico, esto es, el balance de la situación recibida al momento de hacerse cargo de las funciones diplomáticas. En segundo lugar habrá que explicitar el modelo privilegiado y, por último, desentrañar el sentido de la política exterior implementada.

\section{LA SITUACIÓN HEREDADA}

El equipo Nixon-Kissinger- recibió un mandato de difícil ejecución. La situación interior y las notables mutaciones ocurridas en el régimen internacional exigían una respuesta imaginativa y de rápida aplicación.

Los EE.UU. estaban aún "elaborando el duelo" de los grandes proyectos demócratas (Alianza para el Progreso, Gran Sociedad, etc.) y se aprestaban a transitar el difícil camino de la retirada del sudeste asiático.

Los pronósticos aislacionistas ejercían a la fecha notable influencia; estaban basados en las difíciles situaciones internas (conflictos 
raciales, tensión universitaria, etc.) y en acuciantes problemas externos (Medio Oriente, Vietnam, etc.). A pesar de ello, la presunción aislacionista no poclía resistir un análisis riguroso basado en los intereses en juego detrás del globalismo. ${ }^{1}$

Simultáneamente los EE.UU. debían hacer frente a otros desafíos, también externos, originados en la nueva estructuración del régimen internacional, en clonde no pocos factores erosionaban la hege. monía americana.

En el plano de las alianzas occidentales Europa ocupaba un Iugar destacado. La consolidación de un polo económico-político europeo fue percibida como un hecho auspicioso en la medicla que relevaba a los EE.UU. de una serie de compromisos. Sin embargo el supuesto de la complementariedad de intereses entre los EE.UU. y Europa resultó ser más aparente que real.

La Comunidacl Europea era ingobernable para los EE.UU. Después de 1958 los intercambios comerciales intracomunitarios se habían multiplicado por diez y las exportaciones europeas a terceros paises habían crecido en más del $400 \%$. La Comunidad absorbía la mitad de las exportaciones de los países europeos no miembros del Miercado Común, el $60 \%$ de las exportaciones africanas y cerca del $50 \%$ de las del Medio Oriente.

El Mercado Común estaba en tren de desplazar a los EE.UU. como centro motor de los intercambios comerciales mundiales. A esto se le agregaba el peligro subyacente para el cólar en caso de que Europa llevara adelante el viejo proyecto de la zona monetaria europea.

Paradójicamente, al fortalecimiento de la Comunidad Europea se le oponía el debilitamiento de la OTAN. La prosperidad económica socavaba la alianza militar de la misma forma que lo hicieran las tesis independientistas a lo de Gaulle.

Los argumentos económicos, militares y políticos interactuaban positivamente en el sentido de lograr para Europa la ansiada autonomía. Las tesis conciliacionistas a lo Kennedy y a lo Monet estaban superadas y el europeísmo lograba anotar tantos a su favor.

En el Este todavía estaba presente el espectro checoslovaco. Dentro del bloque socialista el debate giraba en torno al reemplazo de las dirigencias heredadas del stalinismo (caso de Polonia y de Alemania) relacionándose este tema con las expectativas de mayor consumo. Estas últimas eran de tal magnitud que ya se perfilaban opi-

1Luciano Tomassini, "La misión imposible del Presidente Nixon", Revista Estudios Internacionales; $\mathrm{n}^{\circ} 12$, enero 70 . Alli se concluye: "La historia y el estado anímico de su país han hecho responsable al Presidente Nixon de poner en práctica la estrategia de retirada. Quizás se le haya encomendado una misión imposible". 
niones favorables a un acercamiento económico con los países capitalistas. Por último, el caso de China ocupaba una situación especial. La URSS necesitaba neutralizar la herejía maoísta; justificar su aproximación a los países capitalistas y responder a las acusaciones imperialistas que China le endilgaba luego de la invasión soviética a Checoslovaquia. Paralelamente, los EE. UU. necesitaban a Pekín como alternativa de chantaje frente a Moscú y como variante de legitimación del orden asiático de post-Vietnam.

El Tercer Mundo aparecía como el convidado de piedra del régimen internacional. Ya para esa 'época eran previsibles las tendencias que más tarde se plasmarían, relacionadas con el común sentimiento de unidad frente a situaciones condicionantes generalizadas. Las ilusiones del Decenio del Desarrollo habían quedado atrás y, como corolario, las tendencias opuestas a cualquier tipo de negociación selectiva con los países desarrollados lograban imponer sus criterios.

Importa también destacar los aspectos económicos heredados por la Administración Nixon y que, sin duda, repercutieron significativamente en el manejo de los asuntos externos."

A partir de 1965 la tasa de beneficios comienza a disminuir en los EE. UU. En ese año la industria americana ocupaba el $90 \%$ de su capacidad productiva mientras que en 1975 esa cifra no superaba el $75 \%$. Simultáneamente la'participación de los EE.UU. en la producción del mundo occidental muestra también elocuentes cifras de deterioro: $70 \%$ en 1950; $57 \%$ en 1965 y $49 \%$ en 1973.

La euforia económica de posguerra fue sucedida por un período de incertidumbres crecientes. El índice Dow Jones daba testimonio de la pérdida de confianza de los círculos económicos. La tarea de reducir las fluctuaciones de la actividad económica a un 'nivel social aceptable terminará por provocar insuperables presiones sobre las tasas de ganancia y sobre Ios precios.'

En el orden te lo militar "la cuenta" heredada también resultaba onerosa. Las relaciones con los aliados y con los países del Este registraban en ese momento un marcado clivage, que llegó a marcar el inicio de una nueva era en 'materia de seguridad.

Con respecto a la OTAN, ya en febrero de 1964 el Secretario de Defensa MC Namara -en una 'declaración ante el Senado- había definido el rol del arma nuclear en Europa. En esa ocasión explícitamente se anunciaba que los EE.UU. renunciaban a la estrategia de la iniciativa nuclear. Era obvio que se estaba abandonando nu-

2Richard Cooper señala la importancia actual de los asuntos económicos internacionales en la gestación de la política exterior en: "Trade Policy in Foreign Policy", Foreign Police, ne 9. 
clearmente a Europa en la medicla que los EE.UU. ya no estaban exentos de sufrir un ataque directo a su propio territorio. Con los años de Gaulle comprobaba la certitud de sus premoniciones.

Respecto del Este la situación militar ‘distaba de ser óptima. La Administración Kennedy no había acertado en definir las reglas de juego con la URSS y a pesar de mantener una clara superioridad lanzó a los EE.UU. a una incomprensible carrera armamentista que no podía sino provocar la respuesta : soviética.

Hasta el momento la estrategia americana era del tipo "anti-ciudad", de manera que en caso de agresión"los EE.UU. se aseguraban una capacidad de destrucción que debía inhibir al adversario. Como la URSS sostenía una concepción similar, se daban las condiciones necesarias para alcanzar un acuerdo basado en la disuasión mínima que evitaría la carrera armamentista que luego sobrevendria.

Al adoptar ambas superpotencias una estrategia "anti-fuerzas" se reconocía la intención de atacar primero para ocasionar la destrucción de los misiles enemigos. También es cierto que con el perfeccionamiento del arma submarina resultó imposible la destrucción del arma de represalia. A la URSS la carrera le significó, entre otras cosas, detener su política consumista, trasladando recursos a la industria bélica. Esto le permitió arribar a la década de los 70 discutiendo la superioridad militar de los EE.UU.

El sistema militar que por naturaleza obró como variable aceleradora del armamentismo fue la ojiva múltiple. Ella es un arma esencialmente desestabilizadora, no sólo porque permite aumentar el número de blancos -y la precisión- sino porque a la vez impulsa a la puesta en servicio de costosos sistemas anti-misiles que recién serán limitados en la fase I de las negociaciones SALT.

\section{IEL PARADIGMA DE KISSINGER}

Desde la llegada de Kissinger al Consejo de Seguridad, su figura fue asociada con un trabajo escrito en 1964: A World Restored: The Politics of Conservatism in a Revolutionary Age. ${ }^{3}$

Generalmente de esta obra se han retenido aquellas ideas referidas al concierto de naciones de la Santa Alianza. Así se perfila la idea generalizada que afirma la existencia de un paradigma kissingeriano basado en la permanente búsqueda !del equilibrio, para lo

3Versión en castellano, Henry A. Kissinger, "Un mundo restaurado", F. C. E., México, 1973. 
cual sería necesario introducir en el régimen a todos aquellos actores que ayudarían a mantener el orden internacional :legitimado.

Hubo actos y gestos que ayudaron a confundir a quienes entrevieron de esa forma el modelo Kissinger. El diálogo con Pekín bien podría constituir un ejemplo de aclscripción a la tesis de lograr el orden a través de la no exclusión de actores significativos. Otras interpretaciones le atribuyeron a Kissinger la idea cle lograr de la URSS y de China el aplacamiento de las iras del Tercer Mundo. Por fin, no faltaron quienes, pensando en la pentarquía, creyeron avizorar el triunfo del europeísmo a costaidel atlantismo.*

Nuestra tesis difiere de las anteriores. Pensamos que la preocupación estratégica central del Profesor Kissinger fue, ;en todo momento, la Unión Soviética. Todos los demás aspectos ocupan entonces un rol. instrumental.

Reconocerle a Europa y al Japón una ubicación expectante dentro del régimen internacional no era sino aceptar la realidad. Incorporar a China continental al diálogo internacional significaba socavar la influencia soviética dentro del Tercer Mundo y Identro del bloque socialista. En suma, hacía falta terminar con la adaptación a una nueva 'realidad internacional en la cual el poder de los EE.UU. no era el de antaño y en clonde resultaba indispensable recomponer la deteriorada posición de USA frente a la URSS.

Hábil táctico y obcecado estratega, Kissinger supo abolir algunas rigideces diplomáticas. Sus viajes, sus declaraciones y sus gestos marcaron una época en la medida que rompieron con un estilo muy tradicional y poco creativo. Esto no significa, de ninguna manera, endosarle el éxito a toda una gestión. Sólo se resaltan las manifestaciones de la flexibilidad táctica puesta en juego.;

El telón de fondo no varió, la URSS siguió ostentando la categoría de enemigo número:uno. Esta herencia de la guerra fría permitió la subsistencia de algunas prácticas no muy heterodoxas que lentamente fueron limitando el campo de maniobra de la diplomacia estadouniclense.

La posición de los EE.UU. frente al Tercer Mundo se explica, en parte, por aquellas rigideces. Si bien no eran previsibles relaciones óptimas entre ambas partes, lo cierto es que ellas se deterioraron hasta un punto muy crítico.

La obsesión por la URSS condujo a privilegiar la dialéctica EsteOeste en detrimento de la Norte-Sur. En la medida que el tema nos atañe pensamos que es útil cletenerse brevemente en las razones que llevaron a la impasse entre los EE.UU. y el mundo en desarrollo.

aUn excelente trabajo sobre la gestión Kissinger se puede encontrar en Marvin Kalb, "Le Secretaire du Monde", Laffont, Paris, 1975. 
La animadversión cle Kissinger por los líderes de los países en desarrollo lo llevó a esquivar, en la medida de lo posible, el diálogo con países todavía envueltos en los azarosos problemas originados por el acceso a la vida independiente. Para Kissinger la conducta de estos líderes constituye la antitesis del paradigma del estadista.

En "Un mundo' restaurado" se expresa claramente esta última idea: "Es el elemento inextricable de .la historia el conflicto entre la inspiración y la organización. La inspiración (cualiclad de los profetas) implica la identificación de sí mismo con el significado de los acontecimientos. La organización (atributo de los estadistas) requiere disciplina, ... la inspiración está fuera del tiempo; su validez es inherente a su concepción. La organización es histórica, depende del material disponible en un período dado... Para ser eficaz en política se requiere la organización, y por esta razón la traducción a términos políticos cle las visiones proféticas siempre falsea las intenciones de sus proponentes".

En la medida del rechazo por los líderes proféticos, la gestión liderada por Kissinger supo de numerosos fracasos, abandonada la diplomacia personal se debió apelar a los carriles institucionales harto deficientes en el manejo con los países del Tercer Munclo.

Erróneamente los EE.UU. intentaron suplir estas falencias apelando a estrategias sustitutivas. La primera de ellas estuvo basada en premisas falsas al ligar a la URSS y a China con las posturas radicales del Tercer Mundo y con los movimientos nacionalistas de liberación. La segunda estrategia consistió en elegir los "hombres llaves", esto es, aquellos líderes (estadistas) que pudieran hacer las veces de interlocutores válidos para determinadas regiones geográficas. Los "hombres llaves" más preciados fueron, para Kissinger, el Sha de Persia y el Presidente egipcio Sadat.

Ambas estrategias son susceptibles de críticas. Pensar que la URSS y China Popular pueden atemperar los ánimos de los radicales del Tercer Mundo constituye un doble error: 1) Significa apostar a que ambas potencias socialistas están interesadas en mantener indefinidamente el status quo; 2) Significa desconocer la autonomía de muchos de los lícleres radicales - caso de Argelia- y de algunos movimientos de liberación, que a lo sumo dependen, relativamente, del abastecimiento de pertrechos bélicos.

En algunas circunstancias los factores atemperantes jugaron en el sentido buscado por los EE. UU., como fue el caso de la crisis del Medio Oriente. Sin embargo, al profundizar el análisis, se advierte que el rol moderador del país socialista (para el caso la URSS) obró en la medida que dicha moderación resultaba funcional para su estrategia con los EE. UU. y también para con sus intereses en la región 
conflictiva. La prueba está en que la URSS jamás rompió con la OLP ni con los países del frente de rechazo (caso Irak).

Hubo otras circunstancias en donde se sobredimensionó la capacidad de influencia que tenían los países socialistas. Poco pudo hacer Pekín para impedir el acceso al poder de los khamers rojos en Cambodia y de la izquierda del Pathet Lao en Laos. Idéntica situación se ofrece en. aquellos casos en donde los "hombres llaves" no han jugado en la dirección buscada para todos los frentes. Así, el sha de Persia no ha dejado de impulsar las tesis alcistas en el seno de la OPEP, a pesar de constituir un aliado fiel de los EE. UU. en otros órdenes.

Es indudable que la diplomacia de $\mathrm{H}$. Kissinger fracasó en la ges. tión de las relaciones con el Tercer Mundo en un momento muy particular de la trayectoria de estos países. La ecuación Norte-Sur no pudo ser resuelta (tal vez sea irresoluble en las actuales circunstancias) y ello repercutió en la performance norteamericana frente al Este, en la medida que la URSS supo aprovechar los vacíos dejados por la diplomacia americana.

\section{LA GESTIÓN KISSINGER}

Generalmente se hace el distingo entre los distintos temas que hacen a las relaciones internacionales. Este tipo de enfoque, si bien presenta algunas ventajas de tipo metodológico, no permite desentrañar y explicar el sentido de los fenómenos internacionales.

Desde nuestra perspectiva, lo político y lo económico resultan indisociables, entendiendo que lo político incluye, además, los temas de seguridad. Queda así delineada nuestra aproximación integradora.

Esta nueva tónica ya es común en el análisis de las relaciones internacionales. Cuando se observan las perspectivas del sistema capitalista ${ }^{5}$ o cuando se discute el contenido y las premisas del nuevo orden económico internacional inevitablemente se debe recurrir al planteo in.tegrador.

Sin embargo, todavía no se han ponderado debidamente las implicancias originadas en los presupuestos implícitos en esta perspectiva analftica. Así los ya célebres debates y/o trabajos refericlos al nuevo

5 Como el debate organizado, en junio de 1975, sobre la "Crisis del Capitalismo" por el Partido Socialista Francés. Ver Le Nouvel Observateur, con Ia participación de F. Mitterrand, M. Rocard, S. Amin, J. Galbraith, J. Timbergen, P. Sweezy, F. Perroux, W. Leontief $y$ otros. 
orden económico internacional soslayan algunas categorías políticas significativas o, directamente, ignoran aspectos tales como las relaciones de pocler que se establecen entre los EE. UU. y la URSS.

Nuestro análisis de la gestión Kissinger está construido sobre esta nueva perspectiva que integró los tres aspectos ya señalados: políticos, económicos y militares. Estos últimos ocupan un Iugar destacado en razón de la trascedencia que ellos tienen para ambas superpotencias.

Hoy dia los temas de la seguridad han trascendido al círculo de especialistas y reciben un tratamiento más cercano a las expectativas de la opinión pública. En los EE. UU. mucho ha contribuido a ello la reciente campaña presiclencial. Al basar algunos candidatos (y precandidatos) sus expectativas en la crítica a la "détente" se despojó al tema de todo tipo de reservas.

Ya se ha considerado la situación heredada por Kissinger en lo que hace a la relación frente a los aliados y vis-à-vis respecto de la URSS. Sintetizando, diríamos que en. los aliados eran cada vez más evidentes las manifestaciones de ingobernabilidad y respecto de la URSS lo más significativo estaba constituido por la resolución soviética de alcanzar la superioridad militar como respuesta al irracional desafío lanzado por la administración Kennedy.

En febrero de 1969 el Secretario de Defensa de los EE. UU. -Melvin Laird- reconoce la superioridad soviética en varios items. Por primera vez se acepta públicamente un hecho que ya venía siendo citado por numerosos analistas. Será el mismo Nixon quien. define el nuevo concepto de seguridad: reemplazar superioridad por suficiencia.

Desde una perspectiva referida especíicamente a la seguridad resulta depreciable la mutación ocurrida. Alcanzar el graclo de primera potencia militar tiene, en realidad, una significación ilimitada respecto de la segunda. Sí es importante el hecho respecto de la posición de ambas potencias frente a terceros países.

La tarea que Kissinger se autoasignó consistió en tratar cle restaurar la posición norteamericana en el mundo y, básicamente, frente a la URSS. Y restaurar era, a fines de la década de los 60, sinónimo de contraofensiva militar (respecto de Moscú) y contraofensiva económica (frente a los aliados díscolos). 
Quienes sobrevaloran los aspectos relacionados con la crisis del sistema capitalista razonan en el sentido inverso al nuestro. Según aquéllos, la inestabilidad de la estructura económica llegó a una situación de peligro tal que para atenderla resultó necesario entenderse con la URSS y China, concentrando los esfuerzos en la sanción a los adversarios económicos ${ }^{6}$. Paradójicamente algunas derechas europeas también coinciden en la apreciación, como es el caso de algunos "barones" del gaullismo. ${ }^{7}$

Reconocer las ventajas alcanzadas por los soviéticos estaba en la naturaleza de las cosas, el problema consistía en la manera de encarar el tema.

Las alternativas ya habian sido definidas con antelación. Se apostaba al remozamiento de la "Doctrina de la Contención" o bien se optaba por una estrategia más sutil: neutralizar a los halcones soviéticos a través de la consolidación de los lazos económicos.

Kissinger optó por esta última alternativa, especulando con las posibilidades de cambio que subyacían en las sociedades socialistas, al mismo tiempo que trataba de ganar tiempo'en favor del reequilibramiento del arsenal norteamericano.

En el terreno militar los' EE. UU. observaban con preocupación el avance soviético en el área de los sistemas antimisiles. En 1962 la URSS había experimentado el antimisil nuclear. Dicha arma amenazaba con desestabilizar la ecuación nuclear y era, por lo demás, sumamente costosa.

Urgía entonces obtener un consenso que alcanzara a algunas reglas de juego fundamentales. La limitación de armamentos jugó ese papel y a través de una falsa imagen se presentó el acuerdo obtenido como un avance en favor de la paz, cuando en realidad sólo se logró congelar el poder mundial.s

Los Acuerdos de mayo de $1972^{\circ}$ básicamente tenían por finalidad la consagración de la "Teoría de la Destrucción Mutua Asegurada", esto es, limitar la carrera en torno a los sistemas antimisiles. De esta forma, al reducir el más sofisticado armamento defensivo, se le

Asi lo thace $S_{;}$Amin en "Une crise structurelle", Revue Minuit, no 9, Paris, mayo 74 .

7Como el ex premier francés M. Debré.

sSobre el tema ver Araujo Castro, "El continente Americano dentro de la Problemática Mundial", Estudios Internacionales, $\mathrm{n}^{\natural 2}$ 20, octubre-diciembre 1972.

9Para los datos específicos de estos Acuerdos ver Horacio Godoy, "Los Acuerdos entre los EE. UU. y la URSS", en Estudios Internacionales, Año VII, n 28. 
restituyó al átomo el podier ecualizador que tuvo en sus orígenes: cada uno a merced del otro.

En estos Acuerdos los EE. UU. reconocieron a la URSS la superioridad soviética ${ }^{10}$ en el número de vectores, con la creencia que durante los 5 años de vigencia del Acuerdo a los soviéticos les sería imposible coronar su superioriclad numérica coheteril con igual ventaja en ojivas múltiples.

Aparentemente Kissinger especuló con las ventajas que contaban los EE. UU. en materia de ojivas múltiples guiadas separadamente (Multiple Independant Re-entry Vehicle, MIRV). O sea, que subestimó a la URSS creyendo que la superioridad de USA en materia de vectores secundarios sería indefinidamente mantenida.

Esta apreciación constituyó una de las equivocaciones más notorias de $\mathrm{H}$. Kissinger. Como atenuante en su favor diremos que la propensión a subestimar a la URSS constituye una de las manifestaciones más comunes del norteamericano, basada en la irracional creencia en. la superioridad del propio sistema.

Si bien en esa época los soviéticos no manipulaban. Ia técnica de la ojiva mltiple, no se pueden soslayar algunos aspectos en donde se evidencian las equivocadas apreciaciones del entonces Consejero Presidencial.

La URSS poseía -y posee- misiles cuatro veces más potentes que los norteamericanos. Respecto de la técnica de la ojiva múltiple digamos que para esa época - mayo de 1972- la URSS sólo poseía ojivas múltiples no guiadas separadamente (Multiple Re-entry Vehicle, O. M). ¿Pero, en qué estado quedaría sumida esta desventaja cuando la URSS alcanzara el manejo de las ojivas MIRV? Seguramente su superioridad sería similar a la que ya poseía en materia de misiles, esto esi una relación de 4 a I en favor de la URSS.

Superados los márgenes de la seguridad absoluta ambas superpotencias apelaron al reaseguro del arma nuclear submarina. Dada la dificultad en localizarla y/o destruirla, el equilibrio quedó nuevamente establecido por la vía de la transformación de la carrera armamentista.

En Moscú se consagró una nueva división internacional de poderes operante en favor de ambas superpotencias al excluir, deliberadamente, a terceros paises. Esta afirmación es fácilmente comprobable al observar las cláusulas relativas al cumplimiento de los acuerdos. Ambos contratantes se comprometieron a utilizar, para esos efectos, los denominados satélites de observación.

Al igual que las cláusulas cle cumplimiento del "Tratado sobre

zoIdem ant. 
prohibición de explosiones nucleares en el espacio" (de 1963), sólo los EE. UU. y la URSS están en condiciones de fijar los límites a su propia carrera armamentista. Esta vez el privilegio consiste en el carácter exclusivo de la información a través del monopolio que ambos países conservan en el campo de los satélites.

Las implicancias que apareja el monopolio ejercido sobre los mecanismos de observación todavía no han sido debidamente justipreciadas por los aliados de ambas superpotencias. Así la URSS pudo manipular el comportamiento de sus aliados del Medio Oriente con ocasión del conflicto de 1973, en la medida que poseía excelente in: formación - proveída por los satélites- del campo de batalla. De igual modo los EE. UU. imponen sus criterios cuando se trata cle determinar la magnitud del potencial bélico de la URSS.11

Otro de los capítulos de interés, también refericlo a los Acuerdos de Mayo, es el relacionado con las lagunas en materia de definiciones referidas a algunos tipos de armamento. Así no se fijó límite alguno al potencial ofensivo. Tampoco se definió la precisión de los vectores nucleares y se ignoraron las armas de destrucción masiva transportadas por avión (dispositiro SRAM de misiles aire-suelo) al igual que los satélites armados.

La existencia de esas lagunas ha provocado no pocos conflictos. Así, los soviéticos han perfeccionado los misiles terrestres "lanzados a frio" (similares a los utilizados por los submarinos) disparados a aire comprimido. De esta forma utilizan un mismo silo para varios misiles, cosa no prevista en los Acuerdos de Mayo, en. donde se limitó el número de silos en el entendimiento que a cada silo le corresponclía un misil.

Otras armas no previstas son los cohetes móviles en tierra (dificiles de observar desde el espacio); el Cruise misile americano (especie de avión robot que vuela a baja altura) y el bombardero de largo alcance (como el bombardero BI de los EE. UU. y el Backfire soviético).

En junio de 1973 el Secretario General del Partido Comunista L. Brezhnev viajó a Ios EE. UU. Los temas de la agenda se dividieron entre la reducción de armamentos y el comercio ruso-americano. Sin haberlo expresado formalmente era obvio que el punto clave, en materia militar, eran las ojivas múltiples.

11El satélite tipo Big Bird es el instrumento utilizado para obscrvar el cumplimiento de las cláusulas del Acuerdo de 1972. El satelite V'ela curnple similar función en el caso del Tratado sobre Explosiones Nucleares. 
Los interlocutores de Brezhnev esta vez no estaban. necesitados de lograr un acuerdo a cualquier precio - esa había sido la circunstancia del $72-$ en la medicla que Nixon no dependia tanto del electorado. Además, las críticas internas provocadas por el acelerado avance soviético en el desarrollo de nuevas armas, también habian provocado el endurecimiento del dúo Kissinger-Nixon..

En el interin las negociaciones de Ginebra relacionadas con las conversaciones SALT se encontraban en una situación de impasse, reclamando los soviéticos la inclusión de las armas tácticas norteamericanas estacionadas en Europa con el propósito de socavar la OTAN.

Coincidiendo con el viaje del Secretario General del P. Comunista soviético, había comenzado a emerger en los EE. UU. la figura del Secretario de Defensa Schlesinger quien, sin ambages, se pronunció en favor de las tesis duras frente a la URSS a la vez que impulsó en forma decidida algunos proyectos significativamente desafiantes para Moscú, v.g. el programa del submarino Trident y del superbombardero $\mathrm{B} 1$.

Bajo este clima poco era lo que se podía lograr en materia de negociaciones SALT. La URSS obtuvo sin embargo algunos resultados, como ser la aprobación americana para la realización de la Conferen. cia sobre la Seguridad y la Cooperación Europea (Conferencia de Helsinki) y logró hacer desaparecer los términos de la Conferencia de Viena sobre la reducción mutua de fuerzas y armamentos que no le convenían. En efecto, en todo momento se omitieron, en. el transcurso de las conversaciones de Washington, los conceptos originales relativos a la reclucción "equilibrada" y "balanceada".

Finalmente nos falta analizar el viaje del Presidente Nixon a la URSS en junio de 1974. En ese momento el escíndalo de Watergate ennegrecía el futuro político del titular del ejecutivo hasta el punto que se llegó a poner en tela de juicio el sentido mismo de la visita presidencial.

Con anterioridad al arribo de Nixon, Brezhner se encargó de complicar el panorama al proponer la suspensión total de la fabricación de nuevas armas lo que, traduciclo, venía a significarle a los EE. UU. la imposibilidad de experimentar los submarinos Trident y los nuevos bombarderos estratégicos.

¿La propuesta soviética perseguía acaso una doble finalidad? Habiendo ya experimentado sus nuevas versiones de misiles XSS y de sus submarinos cle largo alcance $(8.000 \mathrm{~km})$, era obvio que de lograr la URSS su objetivo se alzaría con una ventaja prácticamente inalcanzable. En el caso de fracasar la propuesta ello sería atribuido a la debilidad del Presidente Nixon en momentos que la URSS percibia la necesidad de un reemplazo en el ejecutivo americano. Obvia- 
mente la détente exige, entre otras cosas, de interlocutores en pleno uso de sus atribuciones.

Como era previsible la cumbre de junio de 1974 fracasó. Sólo se firmaron. acuerdos de cooperación menores. En materia cle explosiones nucleares se alcanzaron coincidencias sobre explosiones subterxáneas de una potencia superior a los 150 kilotones (a nada conduce el acuerdo alcanzado cuanclo ambas potencias están tratando de miniaturizar las cargas) $y$, por último, se suscribió un texto referido al sistema No 2 de cohetes antimisiles. En suma, un viaje sin sentido.

La Reunión cumbre de Vlaclivostok en noviembre de 1974 constituyó el "bautismo" internacional del Presidente Ford. Allí los EE. UU. reconocieron la trascendencia de la futura reunión de Helsinki. En materia de reducción de fuerzas en Europa Central la URSS logró imponer el criterio de las reducciones "iguales", descartándose el concepto de reducciones "proporcionales".

En. lo referente a los asuntos comerciales el balance es magro; ambos negociadores declararon su acuerdo para hacer de la cooperación económica un asunto "mutuamente ventajoso". Nacla se dirá en el documento final respecto de los instrumentos y los mecanismos de cooperación.

Lo más sustancial, sin duda, está referido a los aspectos nucleares y que hacen a la esencia de las conversaciones SALT ${ }^{12}$. En la Declaración sobre limitación de los armamentos estratégicos se establece que la fase SALT II estará fundamentada en el principio de la "igualdad y de la seguridad".

In cuanto al detalle de lo acordado, conviene destacar algunas precisiones. Los "pequeños" bombarderos estratégicos y los bombarderos medios escapan a los controles ${ }^{13}$. Se establece que los bombarderos no serán contabilizados como vehículos capaces cle transportar ojivas múltiples (salvo para aquéllos cuya trayectoria supere los $700 \mathrm{~km}$.). Las fuerzas nucleares avanzadas de los EE. UU. en Europa, al igual que las fuerzas atómicas inglesas y francesas, son excluidas de las negociaciones bilaterales. También se amplían las capacidades de

IaSobre la historia de las negociaciones SALT ver The story of SALT, John Newhouse, N. Y., Folt, Richard and Winston, 1973.

13Kissinger debió defender con vigor este aspecto en particular frente al Senaclor Jackson que en esa fecha aspiraba a la caudidatura preidencial. Ver en Le Monde, 10-XII-74, "Kissinger défend vigoureusement l'accord de Vladivostok", por Henri Pierre. 
los silos. En cambio, nada se avanza en materia de limitación de armamentos.

Las excepciones que permite el documento de Vladivostok, son peligrosas en primera magnitud en la medicla que cada parte traspasa la barrera de las 10.000 cargas explosivas, esto es, que ambas potencias pueden destruir 'la totalidad de las instalaciones estratégicas fijas.

La nueva situación estratégica transforma sustancialmente las nociones tradicionales sobre las que se funda el equilibrio militar. La mutación es profunda y se tiene poca conciencia de las implicancias, razonándose todavía con el procedimiento de la analogía basado en una situación inexistente.

Los EE. UU. y la URSS cuentan con el recurso del submarino nuclear. A través de esta arma ambas potencias han logrado simplificar (y lo harán aún más en el futuro) sus teatros de operaciones. A los EE. UU. les resultará posible atacar a la URSS desde sus aguas adyacentes gracias a los misiles que portarán los submarinos Trident (11.000 km. de alcance) mientras que los soviéticos podrán hacer lo mismo desde el Mediterráneo (este mar constituirá para la URSS un verdadero mar interior).

Con el arma submarina surgen nuevas necesidades. No es descartable la posibilidad de proscribir, en un futuro no muy lejano, la limitación de las zonas de patrullaje. $Y$ esto, para Europa, se llama "finlandización". ${ }^{14}$

Hasta aquí se han reseñado las negociaciones referidas a los temas de seguridad. LEstas repercuten sobre aliados y países neutrales en la medida que sobre ellas se elaboran las reglas de juego del régimen internacional, o sea, la forma como se distribuye $y$ asigna el poder entre los actores internacionales.

Sin embargo, al margen de las negociaciones, ambas potencias tratan de obtener ventajas parciales. Explicar entonces la carrera armamentista según el esquema clásico (acción-reacción) resulta anacrónico en la medida que ambos contendores no buscan igualarse sino más bien obtener ventajas irrecuperables. ${ }^{x 5}$

Ha sido aparentemente la URSS quien habria obtenido ventajas crecientes que la estarian separando sensiblemente de los EE. UU. El

wildem ant.

15Referido a la carrera armamentista ver en Revuc Internationale de Sciences Sociales, vol. XXVIII, n9 2, 1976 ("Le cycle infernal de l'armament"), el articulo de Frank Barnaby, "La dinamique des armaments: une vue d'ensemble". 
objetivo perseguido por la URSS sería la obtención del status de "potencia protegida"10. Dicho status se basa en el hecho de contar con un sistema de defensa civil perfeccionado.

Numerosos son los artículos recientes que alertan acerca de la supuesta estrategia soviética. La mayoría de ellos se sustentan en el trabajo del Consejero americano para los problemas de la defensa civil, el Profesor Léon Goure, que lleva el título "La sobrevivencia de la guerra en la estrategia soviética".

El Profesor Goure explica las medidas dispuestas en los últimos años por la URSS clestinadas a organizar la evacuación de las ciudades en el caso de conflicto bélico-nuclear. También habría dispersado la estructura industrial - haciéndola menos vulnerable- y construido inmensos refugios subterráneos provistos de reservas alimenticias considerables. ${ }^{x T}$

Según el rapport del Profesor Goure, la URSS estará muy pronto en condiciones de limitar sus pérdidas en el caso de abatirse una guerra nuclear. En la misma línea se anota el reforzamiento que se estaría llevando a cabo en los silos guardamisiles (diez veces más seguros que los americanos).

La superioridad, hasta el momento cuantitativa, de la URSS y la posibilidad de alcanzar el grado de protección al que se hace referencia permitirian desentrañar una serie de acontecimientos internacionales ocurridos durante los últimos meses.

En un artículo apareciclo en setiembre de 1975 en el órgano mensual del Partido Comunista, el Canciller soviético Andrei Gromyko sostuvo que las fuerzas del Pacto de Varsoria habían acrecentado notoriamente su esfera de influencia. Esas fuerzas tendrían ahora una "preponderancia visiblemente acrecentada y estarían en condiciones de trazar la dirección de la política internacional".

En. aquel momento la frase no fue debiclamente apreciada, sin embargo algunos hechos posteriores llevan a razonar que el tema era más profundo que lo previsto. El Presidente Ford se vio obligado a reformular el concepto de la détente y llegó a definir una "política de paz basada en la fuerza". En el mismo sentido se explayó el Secretario Kissinger con motivo de los sucesos de Angola. En la Asamblea

10Ver en Le Monde, 5 agosto 1976, "L'Union Sovietique cherche-t-elle la superiorité strategique", Michel Tatu. En la misma línea se anota el Informe del Presidente del Comité Militar Aliado, Almirante Sir Peter Fill-Norton (junio de 1976), el estudio del Vicemariscal del Aire S. Menzul (Director del Instituto Real de Servicios Unidos con sede en Londres). Solamente el artículo de M. Tatu aborda el tema del status de potencia protegida.

17En favor de sus tesis el Profesor Goure cita la importancia acreditada por la URSS a la defensa pasiva la que está a cargo de un vice-Ministro y que cuenta con un presupuesto significativo. 
de las Naciones Unidas éste advirtió a Moscú en el sentido que "no puede haber una distensión selectiva" ${ }^{18}$

Más allá de las peripecias electorales en las que se vio envuelta la administración republicana, lo cierto es que el fortalecimiento soviético obligó a redefinir numerosas concepciones y premisas. E1 pensamiento de Kissinger está claramente explicitado en su intervención ante los embajadores americanos acreditados en Europa. ${ }^{10}$

En aquella oportunidad las exposiciones fueron abiertas por el Consejero del Departamento de Estado para el Este, Sonnelfeldt. El nudo de la reflexión. del Consejero consistió en reconocer el nacimiento de la URSS como superpotencia, ante lo cual a los EE. UU. sólo le cabía aprender a convivir con ella especulando con una probable domesticación del sistema soviético.

El razonamiento es inequívoco. Nada pueden hacer los EE.UU. para detener el acceso de la URSS al status de superpotencia. De allí que el único sentido que Sonnenfeldt le atribuye a la détente es la convivencia. En cuanto a los instrumentos utilizables para lograr la domesticación se enfatizan los vínculos económicos que se establecerán con la URSS para poder "terminar con la autarquia soviética".

Volver a la URSS dependiente era, para Kissinger, un viejo proyecto en el cual se ponía a prueba su política de negociar en frentes simultáneos, compensando los problemas excluyentes con los afines. La enmienda Jackson - al establecer correlaciones entre las négociaciones comerciales y el tratamiento que la URSS dispensa a las minorías judías- constituyó el obstáculo que impidió el éxito de la estrategia simultánea.

En otro pasaje de la exposición, el consejero para los asuntos del Este aluclió a la política de los EE. UU. respecto de esos países. La estrategia a la cual se apela es definida en. función de las necesidades existentes de contribuir a la creación de un sistema orgánico en lo que constituye la zona de influencia soviética. Esta propuesta aparentemente iconoclasta se basa en el supuesto de que la manifestación de conflictos entre la URSS y sus aliados podría constituir un problema para la paz. De lo que se trata entonces es de no especular con esas contradicciones en beneficio del equilibrio del régimen internacional. ${ }^{20}$

18Discurso en la Asamblea de la ONU, Nueva York, setiembre de 1976.

19La exposición de Henry Kissinger y de su Consejero fueron hechas en Londres en diciembre de 1975. Públicamente aparecicron en el Herald Tribune del 12 de abril de 1976 .

20Este capítulo de la exposición clespertó airadas réplicas en la prensa europea. Según el Profesor Stanley Hoffman la propuesta de Sonnenfeldt no cs 
Las expresiones vertidas por Kissinger aludieron al comportamiento soviético evidenciado en los conflictos de reciente data. Apa. rentemente, se trató de justificar aquellos gestos soviéticos interpretados por los adversarios de la détente como ejemplos de posturas radicales. ${ }^{2 i}$

La crisis de Angola - como la turca y la portuguesa- es explicada por Kissinger a través de la situación de parálisis provocada por el Congreso al cuestionar al Ejecutivo. Según Kissinger, la URSS sólo se habría aprovechado de esa circunstancia.

La capacidad y la versatilidad de la diplomacia soviética se explica por aquello de la superioridad militar, la que si bien no es decisiva en la relación, bilateral USA-URSS, sí lo es frente a terceros. Por otro lado los EE. UU. sólo pueden evitar que la URSS intervenga en situaciones tipo Angola en la medida que estén en condiciones de impedirlo.

El Profesor Stanley Foffman sostiene la misma idea ${ }^{22}$ basándose en los trabajos del soviético Arbatof, quien hace el distingo entre la esfera de los enfrentamientos de fuerzas sociales en donde la lucha persiste y la esfera de los acuerdos gubernamentales, casos de observación de la détente.

Neutralizada Europa por la vía del entendimiento ruso-americano, corresponde al Tercer Mundo desempeñar el rol de "banco de pruebas" en donde se dirimen los intereses antagónicos. Es necesario entonces detenerse en los últimos gestos soviéticos, en la medida que Moscú ha sabido aprovechar los vacíos y las contradicciones de la diplomacia estadounidense.

Marginado de las discusiones referidas al nuevo orden económico internacional, el mundo socialista no participa en el Diálogo de París. Con la política de low-profile en los foros internacionales -tipo UNCTAD - la URSS ha logrado avances significativos en el continente africano (Angola, Miozambique, Somalía, ¿Namibia?, ¿Rhodesia?).

El sudeste asiático ha sido también testigo de audaces propuestas soviéticas. Sabido es que esta zona es doblemente estratégica para la URSS en la medida que allí confluyen los intereses de China Popular y de los EE. UU. Con vistas a neutralizar a Pekín la URSS está tratando de reactualizar la fracasada propuesta de un Pacto de Seguridad

original, sólo serfa novedosa la presentación. Ver Politique Etrangère, n8 4, 1976, "L'Evolution de Europe et la Politique Américaine".

21 Un análisis pormenorizado de las exposiciones de Kissinger y del Consejero Sonnenfeldt se puede encontrar en Jacques Vernant, "La Doctrine Sonnenfeldt", Revue de Défense Nationale, junio 1975.

astanley Hoflman, art. op. cit. 
Colectiva ${ }^{23}$. Con. respecto a los IE. UU. está tratando de erosionar las relaciones entre aquéllos y sus aliados con la intención de demostrar la inviabilidad de las fórmulas políticas que no incluyen el aval soviético.

La Asociación de Naciones del Sudeste Asiático (ASEAN) ha sido objeto de las atenciones soriéticas en una intensidad desmesurada"4. El muy occidental régimen del Presidente Marcos de Filipinas no sólo reanudó relaciones diplomáticas con la URSS sino que también suscribió un acuerdo comercial por 150 millones de dólares comprometidos en. la compra de azúcar.

La ayuda económica es la carta de presentación soviética en esta zona en donde, como consecuencia de la crisis vietnamita, se duda cada día más del apoyo norteamericano. Algunos ejemplos de la atención que prodiga la URSS son los siguientes: a) cobro de fletes reducidos; b) superavits a favor de esos países; c) ayudai a los planes cle desarrollo; d) créditos para la construcción de centrales hidro. eléctricas $^{25}$; $y$ ayuda para la prospección petrolera (oferta dirigida a Indonesia).$^{26}$

El desarrollo de los recientes acontecimientos y el sucesivo fortalecimiento militar de la URSS han provocado profundas mutaciones, reprochándosele al ex secretario Kissinger debilidad e ingenuidad.

Subsisten numerosas incógnitas, que sólo el futuro dilucidará, referidas al balance de la détence. Entre ellas se destacan las referidas a los resultados de la aproximación económica entre ambos sistemas.

Como se recordará, la interdependencia económica tenía como objeto terminar con la autarquía soviética. Se razonaba que la fortaleza de los vínculos entre ambos sistemas ligaría de manera tal a la URSS que a ésta le resultaría imposible radicalizar sus posiciones. El esfuerzo económico que demanda el armamentismo soviético y el atraso relativo de la estructura industrial hacian. necesario a la

23Al respecto cabe destacar que los regímenes socialistas asiáticos no se mos. traron favorables a dicho Pacto. Así en el XXV Congreso del Partido Comunista soviético (marzo de 1976) sólo Mongolia apoyó la tesis de Moscú. Es más, los Partidos Comunistas de Birmania, Camboya, Tailandia y Malasia no enviaron delegados.

atLa ASEAN agrupa a Indoncsia, Malasia, Filipinas, Singapur y Tailandia.

25Al Tercer Plan Quinquenal de Malasia la URSS contribuyó con $240 \mathrm{mi}$ llones de dólares con un interés del $3 \%$ y a un plazo de 30 años.

noPara la política de la URSS en la región consultar Charles B. Mclane, Soviet Asia Relations, Central Asian Research Center and Columbia University Press, 1973. 
URSS la aproximación al Oeste. Paradójicamente venían a coincidir las necesidades socialistas con los objetivos estadounidenses de la "interdependencia sujetante".

Los resultados de la aproximación económica actualmente provocan incertidumbre en los medios financieros occiclentales. El déficit comercial de los países del Este respecto de los principales países industriales del mundo capitalista superó los 6.000 millones de dólares para el año 1975 (2.400 millones en 1974). En cuanto a las cifras del endeudamiento de los países del COMECON en su conjunto, respecto de los mismos países, superaban en 1975 los $31 \mathrm{mil}$ millones de dólares. El principal deudor es la URSS (13 mil millones de dólares), siguiéndole Polonia (6.000 millones de dólares) ${ }^{27}$

Como dato suplementario cabe recordar que los países del COMECON operan desde 1972 en el mercado del eurodólar, alcanzando esas operaciones el $12 \%$ del total de los empréstitos contratados en esa moneda.

Dejando de lado la seguridad de las transacciones operadas (el Este es un excelente pagador) quienes cuestionan la détente señalan el equívoco occidental consistente en apoyar indirectamente el armamentismo soviético, al permitirle a esos países compensar las falencias de la estructura económica socialista, en áreas tan sensibles como la alimenticia, las de bienes de capital, tecnología, etc.

HELSINKI $X$ VIENA: ¿EL FIN DE EUROPA?

La Conferencia de Helsinki sobre Seguridad y Cooperación Europea celebrada en julio de 1975 constituyó, sin duda, un significativo logro de la diplomacia soviética.

La victoria diplomática en cuestión debe ser medida en función de viejas premisas sustentadas por Moscú desde la posguerra. Ellas hacían referencia al reconocimiento que Occidente debía conceder a las fronteras posbélicas y a la no intervención en los asuntos internos del bloque socialista. $i$

En febrero de 1954, en la Conferencia de Berlín, Molotov propuso, a nombre de la URSS, un "Tratado General sobre Seguridad Colectiva, para Europa". El problema alemán motivaba la propuesta en la medida que restaba clefinir el futuro de la potencia vencida, girando las opciones en torno a la reunificación con neutralización

27Las cifras de referencia aparecieron en Le Monde de l'economie, 31 de agosto do 1976. 
versus división. Este viejo antecedente reflota en HIelsinki y constituye la piedra de toque que subyace detrás cle las tesis de la "consolidación de las fronteras jurídicamente definidas". ${ }^{2 s}$

Hubo también algunas importantes concesiones que permitieron la realización de la Conferencia. Comúnmente se aceptó que aquéllas fueron recíprocas. Así la URSS habría aceptado: ligar Helsinki con las reuniones de Viena sobre la reducción de fuerzas en Europa Central; respetar debidamente los acuerdos de Berlín; moderar su actitud en el Oriente Medio y respetar los derechos humanos como, asimismo, el movimiento de personas y las facilidades de información.

Es el último punto, los derechos humanos, el que ha motivado las críticas de los sectores "duros", quienes alegan que Occidente habría cedido demasiado otorgándole a la URSS un triunfo sin contraparticlas visibles. Esos mismos críticos insisten en pronosticar el incumplimiento soviético de las cláusulas de Helsinki. ${ }^{29}$

Sin entrar a discutir la validez de estas críticas estimamos que las conclusiones allí esbozadas no son correctas en la medida que aíslan la Conferencia del contexto internacional. En efecto, Helsinki es el fruto de largas negociaciones y de concesiones. De éstas la más importante es la que se refiere a las conversaciones de Viena, en donde se encuentran no pocas claves para la comprensión del futuro que le clepara al Viejo Continente.

Iniciadas en 1973, las conversaciones sobre la reducción de fuerzas en Europa Central (Mutual Balanced Forces Reduction, MBRF) estuvieron precedidas por una serie de propuestas ligadas al tema de los contingentes militares estacionados en la región.

El Plan de Rapacki -ex Ministro de Relaciones Exteriores de Polonia- esbozado en 1964, constituye el primer antecedente. Luego sigue el Informe Harmel donde se propone la reducción mutua y equilibrada de fuerzas entre ambos pactos militares. Dos años más tarde, en 1968, el Consejo de la OTAN (reunido en Reykjavik) insiste en la idea del Informe Harmel, correspondiendo (en 1969) al Canciller W. Brandt la tarea de reflotar la idea.

En Viena la URSS trataba de reducir el dispositivo nuclear norteamericano estacionado en Europa. Simultáneamente buscaba garantías respecto de un eventual desarrollo de las fuerzas militares de Alemania Federal. Todo esto sin menoscabar la importancia del evento Helsinki en lo que hace al prestigio de los líderes soviéticos.

Los EE. UU. eran interesados por excelencia en las conversacio-

asVer Richard Dauy, en World Today, vol. 3, n? 31, n8 9, septiembre 1975.

20Un pronóstico pesimista es formulado en $\mathrm{Le}$ Monde por André Fontainc en visperas de la Conferencia de Flelsinki bajo el titulo "Les mots et les choses". 
nes de Viena. El Presidente Nixon sufría las presiones del Senador Mansfield y del Congreso en el sentido de una reducción. unilateral de las fuerzas americanas estacionadas en Europa.

El argumento esgrimido por el Congreso era sensato: el desarrollo de la détente, el auge de las economías europeas y la evolución de la estrategia americana hacian necesario un nuevo tipo de reequilibrio militar entre las defensas avanzadas y las defensas periféricas. Además, el costo de las tropas estacionadas resultaba excesivo.

Corresponde también avanzar en la búsqueda de otros argumentos en la medida que las implicancias de las Conversaciones MIBRF trascienden al restringido campo de las relaciones USA-URSS, proyectando su sombra sobre el continente europeo.

Para los EE. UU. resultaba imprescindible disociar las fuerzas estratégicas estacionadas en el teatro de operaciones europeo. Descle el momento en que el espacio americano había dejado de ser santuario, mal podía interesarle a los EE. UU. el "enganche" entre un eventual conflicto europeo y la entrada en guema del potencial americano. Urgía pues retirar los rehenes nucleares (los soldados americanos convertidos en caución). Para ello era necesario una actitud análoga por la parte soviética y la comprensión de los aliados europeos.

El interés americano en materia de reducciones explica el renunciamiento efectuado en materia de principios. La idea originaria consistía en una reducción "balanceada" y "equilibrada", tesis finalmente descartada ante la intransigencia soviética de mantener el principio de la reducción sin ningún tipo de aditamentos (a la URSS no le interesa perder las ventajas logradas).

Además de:las razones expuestas, que llevaron a los EE. UU. a impulsar las conversaciones de Viena, existen otras que se relacionan con la naturaleza de la alianza atlántica. Generalmente se soslayan estos aspectos cuando es dentro de ellos donde-se tensan los complejos mecanismos referidos al destino de la Comunidad Europea y al papel que le cabe a los EE. UU. frente a sus aliados.

Ya se ha analizado Ia naturaleza y la magnitud del cesafío que Europa le formulaba a USA en la década de los 60 . Obviamente no se podía responder a él de manera convencional. Hacía falta una nueva estrategia y ella es pergeñada por Kissinger.

La estrategia elegida la denominamos "ligada" y consistió en integrar un solo "paquete" que incluía la totalidad de los temas que conforman la agenda de las conversaciones EE. UU.-Europa.

El lanzamiento de la nueva estrategia se produjo el 23 de abril de 1973 en ocasión del Discurso del entonces Consejero Kissinger ante los miembros de la Associated Press. En esa ocasión se anunció el 
chantaje que se realizaria consistente en intercambiax dólares por defensa europea. Alli mismo se le propuso a Europa compartir las responsabilidades frente a una crisis energettica que ya se avizoraba.

Más tarde el Presidente Nixon repitió las ideas de su consejero relacionadas con las prevenciones formuladas a Europa por el proteccionismo de la CEE. Las palabras del Presidente son elocuentes y no se prestan a equívocos: "Cómo conciliar la noción de unidad atlántica en materia de defensa y de seguridad, de una parte, y la política económica de más en más regionalista de la Comunidad Europea". Esta vez los "consejos" se formulaban bajo una atmósfera favorable a los EE. UU., al verse Europa envuelta en plena crisis petrolera.

La "factura" a pagar por la Comunidad Europea era de tal magnitud que sólo cabía la guerra económica. El deseo americano consistía en obtener la reducción. de las exportaciones dirigidas al mercado americano; el aumento de las compras de mercadería "made in USA" y la revaluación de las monedas europeas (o en su defecto, hacerlas flotar en alza). De esta forma sería Europa la que pagaría el déficit de la balanza americana, motivada por la mala gestión económica y' solventada a través de la inflación que le facilitaba el hecho de contar con. la moneda de reserva.

Sin pausa los EE. UU. comienzan a aplicar la estrategia ligada. En el campo económico se buscaba recuperar la perdida hegemonía. Para ello no dudaron en utilizar la amenaza de retirar unilateralmente las tropas estacionadas en. Europa como medio de presión para obtener, de la temerosa Europa, el compromiso de mayores aportes para los gastos de las tropas americanas y el aumento de las compras de productos estadounidenses.

El tema monetario no podía escapar a los ajustes de cuentas realizados por los EE. UU. Finalmente éstos obtienen el régimen de las paridades flotantes, lo que provoca no pocos trastornos en el comercio mundial y que afecta, básicamente, a las economías europeas. En tal sentido resulta conveniente destacar que los EE. UU. pueden marginarse de las turbulencias comerciales con mayor facilidad en la medida que sólo un $5 \%$ de los bienes consumidos en el mercado americano son importaclos, mientras que para Europa esa cifra va de un 20 a un $50 \% .^{30}$

La "factura" americana no termina aquí. En todo momento sus negociadores han tratado de obtener seguridades respecto de la política industrial comunitaria, en el sentido que ella no afectará a la industria americana. De esta forma se pide a Europa que sacrifique

30"Un document Américain", Le Monde Diplomalique, noviembre de 1974. 
una serie de industrias en donde los EE. UU. cuentan con ventajas (aeronáutica, ordenadores, etc.). Todo esto sin olvidar la ofensiva americana sobre la política agrícola de la Comunidad Europea destinada a erosionar los precios comunitarios protegiclos.

La ofensiva de los EE. UU. llega en un momento propicio. No se debe olviclar que hasta la crisis del petróleo la estrategia americana consistía en integrarse de alguna u otra forma con la CEE, buscanclo constituirse en una especie de "socio número 10". Sólo al constatar la fragilidad europea, evidenciada en aquella crisis, Kissinger optó por imponer los criterios americanos tal como se observó en la Reunión de Martinica y en la Declaración, de los Presidentes de la OTAN en junio de 1974.

Las conversaciones de Viena le permiten a los EE. UU. replantear la estrategia militar del bloque occidental. La receta que imponen consiste, entre otras cosas, en la estandarización de los sistemas militares como supuesta alternativa eficientista frente al poderio de los países del Pacto de Varsovia.

Descartada la hipótesis de un enfrentamiento nuclear se revaloriza el armamento clásico. Sin entrar a analizar las virtudes de la estandarización, lo cierto es que el hecho, cle producirse, traería aparejada importantes consecuencias.

De ahora en más se debería privilegiar la competitividad industrial, instaurando a ambos laclos del Atlántico un intercambio de adquisiciones basado en la eficiencia de las respectivas inclustrias de armamentos. Así planteadas las cosas la industria militar europea caminaría hacia su tumba. Idéntica suerte correrían los viejos sueños de la seguridad militar europea.

$\mathrm{Al}$ respecto cabe interrogarse si el triunfo de los aviones americanos YP16 sobre el francés Mirage en el llamado "mercado del siglo" es el inicio de esta nueva política. ¿Acaso la nueva generación de armas guiadas (PGMr: precision guided munitions) no constituirá un negocio exclusivo de los EE. UU.? ? $^{31}$

Para aventar cualquier tipo de sospecha los americanos se han preocupado de presentar los hechos dentro de un marco de aparente objetividad. Así en mayo de 1975 la Comisión de las Fuerzas Armaclas del Senado Americano adoptó la "enmienda Culver-Nunn", en virtud de la cual se autoriza al Secretario de Defensa a rechazar los proyectos de armas americanas que no se adapten a los criterios de

31Sobre el tema consultar Walter Schutze, "Les nouvelles armes guidées avec précision", Revue de Défense Nationale, Paris, marzo de 1976. 
estandarización. Fista ya presenta algunos resultados. Así en el "mercado de los tanques" (el negocio supera los 10.000 millones de dólares frente a los 5.000 que estuvieron en juego con la compra de aviones), Alemania Federal ha podido reservarse una participación sustancial. Simultáneamente ha habiclo casos de renuncias a fabricar determinados armamentos en beneficio cle la estandarización, esto es, evitando superposiciones (el misil submarino inglés "SubMartel" fue sacrificado en favor del misil americano "Sub-Harpoon") .

Otra de las áreas en donde resulta ostensible la presión americana (y que amenaza en convertirse en preocupación sustancial de la diplomacia del Presiclente Carter) es la relacionada con la industria nuclear. Hasta el presente Francia debió sacrificar la venta de equipos de reprocesamiento de plutonio (es el caso de los reactores destinaclos a Corea del Sur) y se encuentran en tratativas las ventas cle ese país a Pakistán, como las de Alemania Federal al Brasil.

Los resultados' 'de la estrategia ligada están a la vista. La Comunidad Europea sufre la mayor de sus impasses; la inclustria europea se termina asociando al capital americano (caso de la informática francesa); la serpiente europea está converticla en :un. "reptil raquítico". En sintesis, el adiós à los sueños protagónicos. 